\title{
Aluminum Intoxication through Leaching in Food Preparation
}

\author{
Suraiya Jabeen ${ }^{1}$, Bisma Ali ${ }^{1}$, Moazzam Ali Khan ${ }^{1}$, Muhammad Bilal Khan ${ }^{1}$, Syed Adnan Hasan ${ }^{2}$
}

\begin{abstract}
This study has been conducted to identify the correlation between food and aluminum intoxication through leaching. The ingestion is the main route of Aluminum exposure to the human body. Hence it is necessary to identify the aluminum levels in human body leached out from aluminum wares and aluminum foil. Pieces of chicken and red meat were baked with different types of solutions containing tomato juice, fresh yoghurt, salt and vinegar in different combinations, they were wrapped in aluminum foil in different combinations, marinated in aluminum pan and were tested for the $\mathrm{pH}$ and weight of pieces and foil. The result showed that citric acid with combination of lactic acid becomes the source for elevated level of aluminum in food items especially in raw beef. Citric acid with combination of tomato juice had highest accumulation rate than other solutions i.e $292.25 \mathrm{mg} / \mathrm{Kg}$ in beef, while chicken leaching rate was $209.52 \mathrm{mg} / \mathrm{kg}$ by the combination of yogurt and lemon juice. The fact still remains that once aluminum exceeds the acceptable limit from daily ingestion of food cooked in these pots, coupled with other sources from the environment. This environmental factor may contribute in increase of neurodegenerative diseases. The aim of this research study is to detect leaching out of aluminum levels from aluminum foil in different food solutions as it is becoming a common practice.
\end{abstract}

Keywords: Aluminum wares, ingestion, accumulation, neurodegenerative diseases, acid.

\section{INTRODUCTION}

Aluminum (Al) as an element represents the third rank for its abundance in crust of earth. This frequently exposes the non-essential metal to water, air and land (Nielsen, 2000). Its attractive chemical and physical properties make it ideal for manufacturing of drugs, cosmetics, food additives and utensils (Ranaua et al., 2001). It has a significant hazard effects on human due to its pervasive nature.

Most of the cookware, used in South Asian countries including Pakistan, is made up of aluminum. Inexpensiveness and heat conductance account for its popularity. Despite being harmless in lower concentrations, high $\mathrm{Al}$ intake results in chronic health effects in long run (Semwal et al., 2006). Use of aluminum utensils for cooking is reported to cause $\mathrm{Al}$ ingestion (Semwal et al., 2006). Major sources of dietary intake include synthetically added aluminum (i.e. grain products, processed cheese and salt) and naturally occurring high aluminum dosages (i.e. tea, herbs and spices). Aluminum erosion from utensils is more likely a minor or inconsistent source. Meat and fish are commonly wrapped in aluminum foil prior to oven cooking. Aluminum can reduce the growth rate of human brain cells, more effectively at higher concentrations (Exley et al., 2001; Zhao et al., 2001). Before 1980, Daily intakes of aluminum were reported to be 18-36 mg per day. In 1987, Joint, F. A. O., \& WHO reported the aluminum intake as $30 \mathrm{mg} /$ day on an average basis and later in 1989 set the Provisional Tolerance Weekly Intake (PTW I) as $7 \mathrm{mg} / \mathrm{kg}$ body weight. Therefore, the acceptable dosage for a $60 \mathrm{~kg}$ person is under $60 \mathrm{mg} /$ day. The aluminum migration from utensils can be regulated by grilling duration, rising temperature due to heating, composition, food $\mathrm{pH}$ value, and presence of any other substances (such as organic acids and salt)(Landry, 2014 ; Shupping, 1996). Aluminum ion can inhibit different metabolic processes in human body by replacing other essential ions i.e. iron, magnesium, calcium, phosphorus, fluoride, etc.

It is one of the common practices to wrap meat items in $\mathrm{Al}$ foil for baking and grilling. However, it was suggested in many studies it develops Al toxicity causing many specific diseases (Rehmani et al., 2010; Carson, 2000).It was also reported that the breast piece of chicken comprises of more aluminum level than the leg. For this reason, food made within aluminum foil may contain high risk for health and addition to other aluminum sources $(\mathrm{Bi}, 1996)$. Aluminum is found to leach out from the foil due to different stimulants; particularly in distilled water as well as in acidic and alkaline media. Aluminum migration is above the permissible limit. Leaching out of aluminum is found significantly lower in alkaline media than in acidic media. Rise in temperature also enhance the rate of migration of aluminum in acidic media. In recent years, there was a continuous use of aluminum foil in cooking process despite the fact that aluminum become the reason for several diseases (Sedman et al., 1985). Past studies also reported that $\mathrm{Al}$ and its compounds are well known toxicants and trigger detrimental effects in household practices. The cooked food in Al containers

\footnotetext{
${ }^{1}$ Institute of Environmental Studies, University of Karachi, Karachi 75270, Pakistan

${ }^{2}$ Department of Applied Chemistry, University of Karachi, Karachi 75270, Pakistan

*Corresponding Author sujabeen@uok.edu.pk

Received November 14, 2016, Accepted November 24, 2016
} 
may carry Al compounds to digestive system through ingestion which is then proliferated to different parts of the body by blood (Exley et al., 2006; Gies, 1911).

Many researches revealed the neurological effects of Al ions on human health such as Alzheimer disease (Perl and Brody, 1980; Walton, 2006), other adverse consequences like Dialysis Encephalopathy (Shaw et al. 2008; Tomljenovic, 2013), and Amyotrophic Horizontal Sclerosis (Shaw and Höglinger, 2008, Tomljenovic, 2011) (Table 1). Patients for Alzheimer's disease, Parkinson disease and dialysis encephalopathy have high Aluminum concentrations in their brain tissues (Soni et al., 2001; Tabrizi, 2007). Aluminum crosses the blood brain barrier (BBB) and accumulates in brain. It is also accumulating in bones and liver, therefore, it's significantly damaging to patients with bone disease or renal dialysis, especially toxic to the elderly peoples and patients of kidney failure (Ranau et al., 2001; Soni et al., 2001). According to the neurological, mental disorders, development and substance (NMDS) there is a rise in neurological and mental disorders in the world and this rise is mainly due to the increase in the number of individuals reaching the age that is most susceptible to many of above mentioned disorders i.e old age (Murray et al., 2013; Spencer, 2013). This elevation will be steeper in middle and low income region of the world yielding long term effects like trauma, infectious disease and malnutrition, which associated to the development of these disorders that in turn lead to early death or a lifetime of disability (Silberberg et al., 2015).

$\mathrm{Al}$ ions in the human diet are non-bio available from the small intestine, because their hydrated charge unable to penetrate the lipid protein membranes of the duodenal mucosa (Ranaua et al., 2001). Ingested Al is found in blood in form of ligand and is subsequently conveyed to different organs of the body. As in high concentration $\mathrm{Al}$ is toxicant in tissues, bones, lungs (Osipova, 2015)and may enters central nervous system (CNS) after blood crossing the Blood Brain Barrier (BBB) (Yokel, 2006).

Cerebrum and bone malady due to large amounts of aluminum in the body have been detected in kids with kidney illness. In these kids, the bone harm is brought by aluminum in the stomach keeping the assimilation of phosphate, which is required for sound bones. Aluminum can be transferred through bosom milk to a newborn child but at low concentrations (Al Fact Sheet, 2011). Al concentration is detected in infant formula milk twice from the stated recommended level for drinking water $(50 \mu \mathrm{g} / \mathrm{L})$ and 14 of these milks exceeding the maximum permissible limit level for drinking water according to European Union $(200 \mu \mathrm{g} / \mathrm{L})$ (Boyd 2000, Chuchu et al., 2013).

It has been noticed that salty and acidic foods like apple puree, rhubarb, tomato puree or salted herring packed in aluminum-based skillet, bowls, and foils may have aluminum concentration (Public health statement, 2008). Additionally, the utilization of aluminum vessels contained fast food have expanded the aluminum levels, particularly in food that contains tomato, pickles, and vinegar (As they are acidic) (Shaw and Tomljenovic, 2013).

The aggregate weight of aluminum in healthy people is $30-50 \mathrm{mg}$. approximately half of the weight is in the skeleton and $25 \%$ is in the lungs. In lungs, aluminum level increases with age. Aluminum levels in bone tissue of healthy people range from 5 to $10 \mathrm{mg} / \mathrm{kg}$. Serum levels in healthy people range $1-3 \mathrm{ug} / \mathrm{L}$ (Larsen, 2008). The aim of this research study is to detect leaching out of aluminum levels from aluminum foil in different food solutions as it is becoming a common practice.

\section{MATERIALS AND METHODS}

This study conducted in two parts, in the first one Al leaching was checked in beef and chicken meat samples and in another part a survey study was conducted to evaluate the $\mathrm{Al}$ toxicity awareness in people of Karachi.

Eight specimens of aluminum foil had been cut into rectangular dimensional shape of $5 \times 8 \mathrm{~cm}$. Each of them was immersed in different solutions of different concentrations except one piece of aluminum foil which was taken as a control. Solutions of tomato juice, yogurt, citric acid, lemon juice and red grapes vinegar had been prepared. Control piece of aluminum foil without any treatment was kept in tap water for boiling in steel pan of diameter of $12 \mathrm{~cm}$.

Beef meat, chicken meat, tomato juice, salt, citric acid, red grape vinegar, yogurt and lemon juice and $\mathrm{Al}$ foil (Diamond Aluminum Foil, USA made) were purchased from local market of Karachi. The work performed at $180^{\circ} \mathrm{C}$ in gas oven.

Aluminum cooking utensils were chosen from local market of Karachi. These utensils were washed and cleaned. Different specimens were put in different environment in separate utensils. Beef meat pieces of 20 gm each were pre weighed in an electrical balance (Libror AEG-120Shimadzu) marinated overnight in different solutions and remaining one of the piece kept as control with no marination. An experiment of aluminum leaching from aluminum utensils was performed in vapor phase at $180^{\circ} \mathrm{C}$ in an oven. 
Table 1. Aluminum associated with neuronal injury

\begin{tabular}{lll}
\hline Neurological findings & Neurotoxic effects & References \\
\hline Amyotrophic lateral sclerosis & Degenerative changes in motor neurons & Chang and Dyer (1995) \\
Alzheimer's disease & Loss of cognitive function & Adams and Duchen (1992) \\
Dialysis encephalopathy & Myoclonic jerks & Baltimore, Williams, and Wilkins (1980) \\
Hearing deficit & Cell loss in corti, spiral ganglion & Ohlemiller and Frisina (2008) \\
Dementia & Intellectual debilitation & Flaten, (2001) \\
\hline
\end{tabular}

Different additives were used to prepare the following food solutions:

Solution A: $20 \mathrm{~g}$ meat piece $+100 \mathrm{ml}$ tomato juice (Felvuric acid) $+5 \mathrm{~g}$ of citric acid $+2 \mathrm{~g}$ of salt.

Solution B: 20 gm meat piece $+100 \mathrm{ml}$ of tomato juice $+5 \mathrm{ml}$ of red grape vinegar (Acetic acid) $+2 \mathrm{~g}$ of salt.

Solution C: $20 \mathrm{~g}$ meat piece $+5 \mathrm{~g}$ of yogurt (Lactic acid) $+20 \mathrm{ml}$ of lemon juice (Citric acid).

The $\mathrm{pH}$ of each solution was measured before the experiment. To assure consistency, all the experiment was done with perfection.

The above food solutions with meat after marinating for 16 hours at $10^{\circ} \mathrm{C}$ in refrigerator were kept in an oven within an aluminum pan and each marinating meat piece was wrapped in an aluminum foil. The control piece of meat without marinating and without foil baked in a separate pan at same temperature for same period. $\mathrm{Al}$ was baked at $180^{\circ} \mathrm{C}$ for 1.5 hour. The meat pieces were weighed before and after the experiment.

All the aluminum levels were estimated by using polarized Zeeman atomic absorption spectrophotometer model no Z- 8000 Hitachi. An estimation of aluminum was done by standard method of atomic absorption spectrophotometer (Sullivan et al., 1986).

\section{Weight loss measurements}

The aluminum foil specimens were cut into $5 \times 8 \mathrm{~cm}$ pieces then weighed by using sensitive electrical balance and immersed completely in solutions of different concentrations (A,B, and C) using additives mentioned above.

The $\mathrm{pH}$ of the solutions was noted before every experiment. The foil samples were immersed completely in solutions within different aluminum pan of diameter $12 \mathrm{~cm}$ and kept for baking in an oven at $180^{\circ} \mathrm{C}$ for 1.5 hour. Each specimen after baking was washed with distilled water. One specimen of foil was kept for boiling for 20 minutes in $300 \mathrm{ml}$ of tap water within steel pan. All the specimens were kept for drying out in air and then each of them was weighed again.
The difference in weight before and after an experiment was noted.

\section{Survey}

A survey study was performed on randomly selected samples of 86 people in different districts of Karachi. The data was collected in the month of October 2015. The target groups were personnel which were involved in field of medicine especially neurologists, residents of different towns of Karachi particularly housewives and students of universities. Questionnaires were given to these people to evaluate the information concerning aluminum effects on human health and awareness about Al toxicity. The study proved to be beneficial in terms of disseminating information to the layman regarding aluminum leaching from foil and cooking wares to the food and causing neurological disorders. The participants were asked for details of personal information including their age, gender, occupation, residential area and monthly income as well as their educational status. Other questions were about usage of aluminum utensils including: For how long they are being used, quantity of aluminum utensils if using, type of food cooked in aluminum wares, the effects of using aluminum cooking wares and symptoms regarding aluminum toxicity. Questionnaire also covered the comments from the personnel associated with aluminum cooking wares and its effects. Participants were asked 30 random questions which are mostly of one word answers.

\section{RESULTS}

Table 2 lists a summary of gender, educational status, and occupation of participants. $77.9 \%$ were female and only $22.09 \%$ were male, as more females are involved with cooking and baking. Table 3 summarized the awareness level of participants regarding aluminum toxicity and responses to the questions. About 39.53\% participants used aluminum cooking wares in their kitchen and considered the availability of wares as the most important reason to be used. $48.83 \%$ were using Al utensils because of it easy availability and 23.25 for its good quality. $37.20 \%$ of participants heating the Al utensils for 3-4 hours. As exposure time is another significance factor for aluminum toxicity hence $55.81 \%$ 
participants exposed to aluminum pans for about 1-2 hours continuously. $33.72 \%$ participants used tomato juice as souring agent in aluminum utensils whereas yogurt and lemon juice also has been used by many of the participants. $47.67 \%$ of participants reported the use of steel wool for cleaning aluminum cooking wares and that enhanced the leaching process of aluminum metal in food. About half of the participants preserved food that was cooked in aluminum utensils. More than half i.e. $45.34 \%$ participants used yogurt for marinating of food stuff. Addition of lemon enhanced the mechanism activity of aluminum metal but unfortunately $60.46 \%$ respondents used agent that had lemon in it as a dish washer. Another tragedy reported that $63.95 \%$ participants felt adverse effects of aluminum i.e, memory loss, abdominal pain, digestion problems etc.

\section{DISCUSSION}

The cooking pattern has been changed since many past years as more and more cooking is done with souring agents like tomato, lemon, vinegar is easing the Al leaching in food. Al exhibits a passive behavior in aqueous solutions due to a protective compact $\mathrm{Al}_{2} \mathrm{O}_{3}$ film on its surface. However, the solubility of this protective film increases in acidic and alkaline medium. According to Al Juhaiman (2010), Al erosion in aqueous solutions may be explained by the acidic medium chemical reaction occurring on the surface of the $\mathrm{Al}$ cookware. $\mathrm{Al}$ is the metal used in utensils in Pakistan and many other South Asian regions. Normally it does not have ill health effects but cooking in this region involved with many of the acidic substance that helps in enhancing the Al leaching. Previous result showed that most of participants were aware of toxicity regarding aluminum before the mentioned survey. Many of the participants used aluminum wares in their kitchens and considered many reasons for its effective used i.e, easy availability, better quality, taste factor etc. Heating in aluminum pan enhanced the process of leaching in food items and it would be more toxic if used with citric acid and salts (Bi, 1996). The results revealed that the aluminum ingestion by most of the people caused many adverse effects to them as well as to the environment. The survey also includes the awareness, knowledge of increased use of aluminum from past few years. And the burden of neurological diseases all over the worldwide particularly in middle and low income countries because aluminum utensils are comparatively cheaper than other types of cooking wares even survey also showed the same result (Silberberg et al., 2015).
Table 2. Demographic Data of study participants according to descriptive features

\begin{tabular}{lcc}
\hline Gender & N & Percentage \\
\hline Male & 19 & 22.09 \\
Female & 67 & 77.90 \\
Educational status & & \\
Graduate & 29 & 33.72 \\
Undergraduate & 25 & 29.06 \\
Post graduate & 10 & 11.62 \\
Doctors & 10 & 11.62 \\
Others & 12 & 13.95 \\
Occupation & & \\
Housewife & 24 & 27.90 \\
Student & 40 & 46.51 \\
Doctors & 10 & 11.62 \\
Others & 12 & 13.95 \\
\hline
\end{tabular}

Figure 1 showed a number of symptoms appeared due to toxicity of aluminum metal, Dementia and abdominal pain appeared in $18.60 \%$ of the participants, nervousness in $16.27 \%$ participants. Low number of respondents has trouble while sleeping but about $23.25 \%$ of the participants felt gain or loss in weight without diet. About $26.74 \%$ of the participant's cases reported with frequent headache or migraine while only $15.11 \%$ of the participants have problem of excessive worry.

Level of aluminum accumulation and to identify that which solution has most leaching property in food stuff, equation shows the result:

$$
\text { Aluminum intake } \mathrm{mg} / \mathrm{kg}=\frac{\mathrm{Conc} \times 25}{40 \times \mathrm{Wt} \times \text { Dil factor }}
$$

Where; Concentration is equal to concentration of blank minus solution, Wt. is the weight of the sample with product of dilution factor (Bassioni et al., 2012).

Table 4 illustrated the summarized experiment and aids to determine the most leaching effect of solution added with different concentrations of solutions. The results show the leaching effect of aluminum foil in beef as well as chicken meat. Solution A has more intense leaching of aluminum metal in beef meat whereas less in solution B. However, in chicken meat highest leaching rate is in solution $\mathrm{C}$ (yogurt + lemon) and least in solution $\mathrm{A}$ which having $\mathrm{pH}$ 3. These results emphasize the previous work which reported that the amount of aluminum, accumulated in food during the preparation process, depends on the $\mathrm{pH}$ value and the cooking time (Ranau et al., 2001). Results showed that Solution A (citric acid) is the most active for leaching among the used acids. Ingestion is major route for exposure to general public. 
The acidic substance in stomach would help in solubility of aluminum compounds into single molecules $\mathrm{Al}^{+3}$. Estimation of bioavailability of aluminum is to be in range of $0.3 \%$ when taken orally in humans, whereas the bioavailability of aluminum from food and beverages generally is considered to be lower, about $0.1 \%$. However, it might be possible that oral absorption of food contaminated with aluminum can vary at least 10 -fold depending on the chemical forms present (Abercrombie and Fowler, 1997).

The beef samples taken as control showed $0.005 \mathrm{mg} / \mathrm{L}$ and control chicken meat gave $0.001 \mathrm{mg} / \mathrm{L}$ $\mathrm{Al}$, i.e almost negligible as these were not treated with acidic content so did not work for leaching.

Table 3. The distribution of participants' responses to informative questions

\begin{tabular}{|c|c|c|}
\hline Questions & Response & Percentage \\
\hline \multicolumn{3}{|c|}{ Awareness of aluminum toxicity } \\
\hline Yes & 44 & 51.16 \\
\hline No & 42 & 48.83 \\
\hline \multicolumn{3}{|c|}{ Aluminum usage in kitchen } \\
\hline Yes & 34 & 39.53 \\
\hline No & 52 & 60.46 \\
\hline \multicolumn{3}{|c|}{ Reason for using aluminum wares } \\
\hline Cheap & 6 & 06.97 \\
\hline Quality & 20 & 23.25 \\
\hline Availability & 42 & 48.83 \\
\hline Life style & 18 & 20.93 \\
\hline All & 0 & 0 \\
\hline \multicolumn{3}{|c|}{ No of cooking hours in aluminum pans } \\
\hline $1-2$ hours & 48 & 55.81 \\
\hline 3-4 hours & 32 & 37.20 \\
\hline 5-6 hours & 6 & 06.97 \\
\hline More hours & 0 & 0 \\
\hline \multicolumn{3}{|c|}{ Souring agent used } \\
\hline Tomato & 29 & 33.72 \\
\hline Yogurt & 23 & 26.74 \\
\hline Lemon juice & 9 & 10.46 \\
\hline Tamarind & 0 & 0 \\
\hline Vinegar & 5 & 05.81 \\
\hline All & 20 & 23.25 \\
\hline \multicolumn{3}{|c|}{ Cleanliness of aluminum utensils } \\
\hline Foam & 42 & 48.83 \\
\hline Steel wool & 41 & 47.67 \\
\hline Brush & 3 & 03.48 \\
\hline \multicolumn{3}{|c|}{ Marinating agent } \\
\hline Vinegar & 16 & 18.60 \\
\hline Tomato & 17 & 19.76 \\
\hline Yogurt & 39 & 45.34 \\
\hline Lemon juice & 14 & 16.27 \\
\hline \multicolumn{3}{|c|}{ Dish washer (added with lemon) } \\
\hline Yes & 52 & 60.46 \\
\hline No & 34 & 39.53 \\
\hline \multicolumn{3}{|c|}{ Adverse effects of Al toxicity } \\
\hline Yes & 55 & 63.95 \\
\hline No & 31 & 36.04 \\
\hline
\end{tabular}




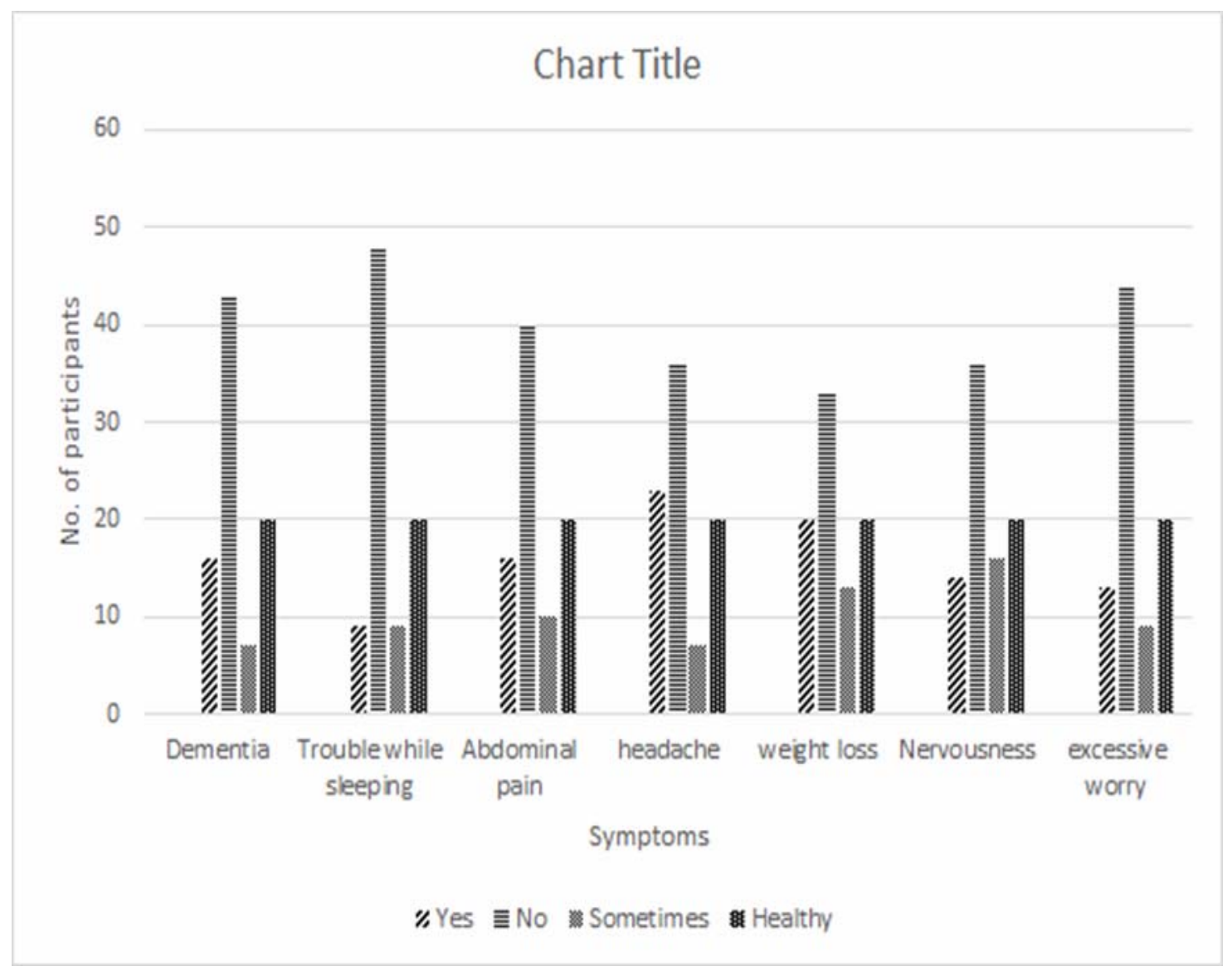

Figure 1. Responses to symptoms of Aluminum Toxicity

Table 4. Effects of different food solutions on leaching of aluminum

\begin{tabular}{clccc}
\hline Solution code & Solution & $\mathbf{p H}$ & $\begin{array}{c}\text { Aluminum intake in } \\
\text { beefmg/Kg }\end{array}$ & $\begin{array}{c}\text { Aluminum intake in } \\
\text { chickenmg/Kg }\end{array}$ \\
\hline A & $\begin{array}{l}\text { 100ml tomato juice+ } 5 \text { gm of citric } \\
\text { acid }+2 \text { gm of salt }\end{array}$ & 292.25 & 34.16 \\
\hline B & $\begin{array}{l}100 \mathrm{ml} \text { tomato juice }+5 \mathrm{ml} \text { of red } \\
\text { grapes vinegar }+2 \mathrm{gm} \text { of salt }\end{array}$ & 6 & 3.357 & 159.36 \\
\hline C & $\begin{array}{l}\text { 5gm of yogurt }+20 \mathrm{ml} \text { of lemon } \\
\text { juice }\end{array}$ & 4 & 16.898 & 209.52 \\
\hline Control & Control without any treatment & 7 & 0.005 & 0.001 \\
\hline
\end{tabular}

Mean of triplicate were taken for each sample

Table 5 shows that the corrosion rate of aluminum raises with the low $\mathrm{pH}$. Similar behavior is reported by Wong and Alkire (1990). Other reported that aluminum is very sensitive to high $\mathrm{pH}$ and shows a corrosion increase in alkaline environments. This result is almost similar to previous work by Al Zubaidy et al., (2011) also Bi (1996) indicated that leaching enhanced dramatically in the ranges of $\mathrm{pH}<4$ or $\mathrm{pH}>8$.

\section{Foil experiment}

Effect of aluminum foil on different food solutions has been estimated. The result of this experiment helps to determine that whether foil leach or not into the food. The corrosion rate in $\mathrm{mg} \cdot \mathrm{cm}^{-2} \cdot \mathrm{hr}^{-1}$ is calculated using the following equation:

$\mathrm{CR}=\underline{\mathrm{WL}}$

$$
\mathrm{A} \times \mathrm{T}
$$

Where WL is weight loss in mg of aluminum foil, A is the cover area of aluminum foil specimen in $\mathrm{cm}^{2}$ and $\mathrm{T}$ is time of baking in hour (Bassioni et al., 2012; Muslim et al., 2014). 
Table 5. Corrosion rate of aluminum foil on different food solutions

\begin{tabular}{llcc}
\hline Solution Code & Solution & pH & Corrosion rate $\mathbf{~ m g} / \mathbf{c m} 2 * \mathbf{h r}$ \\
\hline $\mathrm{A}$ & $100 \mathrm{ml}$ tomato juice $+5 \mathrm{~g}$ citric acid $+2 \mathrm{~g}$ salt & 3 & $7.916 \times 10-4$ \\
$\mathrm{~B}$ & $100 \mathrm{ml}$ tomato juice $+5 \mathrm{ml}$ of red grapes vinegar +2 gsalt & 6 & $1.686 \times 10-3$ \\
$\mathrm{C}$ & 5 gm yogurt $+20 \mathrm{ml}$ lemon juice & 4 & $2.926 \times 10-3$ \\
Control & Control (without any treatment) & 7 & $1.02 \times 10-5$ \\
\hline
\end{tabular}

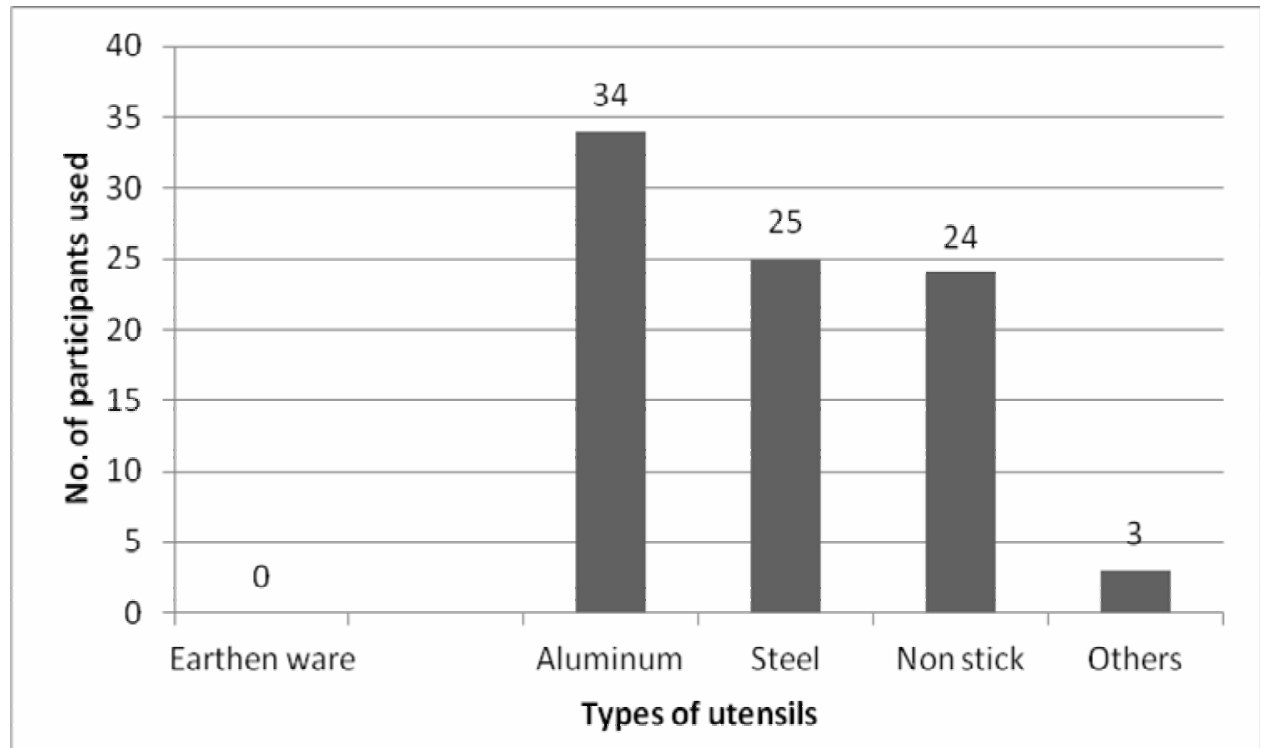

Figure 2. Types of utensils used by No. of participants

\section{CONCLUSION}

The investigation reached a conclusion that all the specimens exposed to aluminum clearly had increased concentrations of aluminum metal after marinating and cooking. There were many factors that became the source of elevated level of Aluminum such as exposure time, cover area, type of utensil (steel, aluminum, earthen) temperature etc. Souring agent used in food for marinating is another major reason for migration of aluminum in food stuff. But the test identifies that citric acid has $292.25 \mathrm{mg} / \mathrm{Kg}$ of aluminum leaching rate in beef meat whereas yogurt has most leaching effect in chicken meat. Probably this migration process depends upon certain factors for instance; $\mathrm{pH}$ of food, chemical composition of raw material, temperature of cooking ware, presence of any organic acids and salts. The fact still remains that once aluminum exceeds the acceptable limit from daily ingestion of food cooked in these pots, coupled with other sources from the environment, diseases such as loss of memory, damage to central nervous system, dementia, severe trembling, and lethargy have adverse effects on health. An aluminum tolerable daily intake of $1 \mathrm{mg} / \mathrm{kg}$ body weight /day as an easily excreted limit has been established by the World
Health Organization (WHO) of the United Nation (UN) (Joint and WHO 2000). Unfortunately, the ingestion is more than what human bodies can handle. More than half of the wares sold are made up of aluminum. Aluminum utensils are often coated with nonstick finishing.

\section{RECOMMENDATIONS}

Aluminum pans should not be heated dry because it might cause metal to be leached out and could harm the person exposed. Utensils like earthen wares, iron, steel wares would be a better option. Old aluminum pots had the highest concentration of leaching while new steel pots had the least leaching of aluminum. Hence it would be better not to use aluminum utensils for long period of time for cooking acidic foods causing metal leaching, although provisional daily intake given by WHO is $1 \mathrm{mg} / \mathrm{kg}$ of the body weight per day (WHO, 2014). Storing highly acidic or salty foods such as tomato sauce, rhubarb or sauerkraut in aluminum pots is not recommended. The acid in these foods may cause more aluminum leaching rate than usual to enter the food and can cause pitting on the pot's surface. 


\section{REFERENCES}

Abercrombie, D. E., and R. C. Fowler. 1997. Possible aluminum content of canned drinks. Toxicology and industrial health 13: 649-654.

Adams, J.H., and L.H Duchen. 1992. Greenfield's Neurological, $5^{\text {th }}$ Edition, New York, Oxford University Press.

Al Fact Sheet _ 20110728 Potential Health Effects from Exposure to Aluminum and Aluminum Compounds.

Al Juhaiman, L. A. 2010. Estimating Aluminum leaching from Aluminum cook wares in different meat extracts and milk. Journal of Saudi Chemical Society 14: 131-137.

Al Zubaidy, E. A., F. S. Mohammad and G. Bassioni, 2011. Effect of $\mathrm{pH}$, salinity and temperature on aluminum cookware leaching during food preparation. Int. J. Electrochem. Sci. 6: 6424-6441.

Baltimore,C. M. Williams, and A. Wllkins. 1980. Experimental and Clinical Neurotoxicology, Spencer PS and Schaumburg Hli, eds. OXFORD UNIVERSITY PRESS.

Bassioni, G., F. S.Mohammed, E. Al Zubaidy, and I.Kobrsi. 2012, Risk assessment of using aluminum foil in food preparation. Int. J. Electrochem. Sci.7: 4498-4509.

Bi, S. 1996. A model describing the complexing effect in the leaching of aluminum from cooking utensils. Environmental pollution 92: 85-89.

Boyd, C. E. 2000. Water quality (pp. 52-83). Blackwell Publishing Ltd.

Carson, B. L. 2000. Aluminum compounds: Review of toxicological literature. Abridged final report, National Institute of Environmental Health Sciences. Integrated Triangle Park, North Carloina, 27709.

Chang, L. W. and R. S. Dyer.1995. Handbook of neurotoxicology (Vol. 36). Informa Health Care.

Chuchu, N., B. Patel, B. Sebastian, and C. Exley.2013. The aluminum content of infant formulas remains too high. BMC Pediatrics 13: 1-7.

Exley, C., O. Korchazhkina, D. Job, S. Strekopytov, A.Polwart, and P.Crome. 2006. Non-invasive therapy to reduce the body burden of aluminum in Alzheimer's disease. Journal of Alzheimer's Disease 10: 17-24.

Flaten, T. P. 2001. Aluminum as a risk factor in Alzheimer's disease, with emphasis on drinking water. Brain research bulletin 55:187-196.

Gies, W. J. 1911. Some objections to the use of alum bakingpowder. Journal of the American Medical Association 57 : 816-821.

Joint, F. A. O., \& WHO Expert Committee on Food Additives. 1987. Evaluation of certain food additives and contaminants (No. 759). World Health Organization.

Joint, F. A. O., \& WHO Expert Committee on Food Additives. 2000. Evaluation of certain food additives and contaminants. World Health Organization technical report series, 896,1 .
Larsen, J. C. 2008. Scientific Opinion of the Panel on Food Additives, Flavourings, Processing Aids and Food Contact Materials on a request from European Commission on Safety of aluminium from dietary intake.

Murray, C. J., T.Vos, , R.Lozano, M.Naghavi, A. D. Flaxman, C. Michaud, V. Aboyans. 2013. Disability-adjusted life years (DALYs) for 291 diseases and injuries in 21 regions, 1990-2010: a systematic analysis for the Global Burden of Disease Study 2010. The lancet 380(9859): 2197-2223.

Muslim, Z. R., H. I. Jaafer and M. Q. Fahem. 2014. The effect of $\mathrm{pH}$ level on corrosion rate of Aluminum and copper. International Journal of Basic and Applied Science. 2: 89-92

Nielsen, F. H. 2000. Evolutionary events culminating in specific minerals becoming essential for life. European journal of nutrition 39: 62-66.

Ohlemiller, K. K., and R. D. Frisina. 2008. Age-related hearing loss and its cellular and molecular bases. In Auditory trauma, protection, and repair (pp. 145-194). Springer US.

Osipova, N. A., K. A. Filimonenko, A. V. Talovskaya, and E. G. Yazikov. 2015. Geochemical Approach to Human Health Risk Assessment of Inhaled Trace Elements in the Vicinity of Industrial Enterprises in Tomsk, Russia. Human and Ecological Risk Assessment 21: 1664-1685.

Perl, D. P., and A. R. Brody. 1980. Alzheimer's disease: Xray spectrometric evidence of aluminum accumulation in neurofibrillary tangle-bearing neurons. Science, 208: 297299.

Public health statement, 2008, Division of Toxicology and Environmental Medicine.

Ranau, R., J. Oehlenschläger, and H.Steinhart. 2001. Aluminum levels of fish fillets baked and grilled in aluminum foil. Food Chemistry 73: 1-6.

Rehmani, F. S., Tanoli, S. A. K., Ambreen, S., M. Rashid, S.S. Abbas, andA. Shafique. 2010. Competition of aluminum on iron binding site in the biological system. Journal of the Chemical Society of Pakistan, 32: 467-470.

Sedman, A. B., G. L. Klein, R. J. Merritt, N. L. Miller, K. O. Weber, W. L. Gill and A. C. Alfrey. 1985 . Evidence of aluminum loading in infants receiving intravenous therapy. New England Journal of Medicine 312: $1337-$ 1343.

Semwal, A. D., A. Padmashree, M. A. Khan, G. K. Sharma, and A. S. Bawa. 2006. Leaching of aluminum from utensils during cooking of food. Journal of the Science of Food and Agriculture 86: 2425-2430.

Shaw, C. A. and G.Höglinger. 2008. Neurodegenerative diseases: neurotoxins as sufficient etiologic agents?.Neuromolecular medicine 10: 1-9.

Shaw, C. A., and L. Tomljenovic. 2013. Aluminum in the central nervous system (CNS): toxicity in humans and animals, vaccine adjuvants and autoimmunity. Immunologic Research 56: 304-316. 
Shupping, B. A 1996.Model describing the complexing effect in the leaching of aluminum from cooking utensils. Environmental Pollution 92:85-89.

Silberberg, D., Anand, N. P., Michels, K., and Kalaria, R. N. 2015. Brain and other nervous system disorders across the lifespan [mdash] global challenges and opportunities. Nature, 527: S151-S154.

Soni, M. G., S. M.White, W.Flamm and G., Burdock. 2001. Safety evaluation of dietary aluminum. Regulatory toxicology and pharmacology 33: 66-79.

Spencer, S. 2013. Global Burden of Disease 2010 Study: a personal reflection. Global Cardiology Science and Practice, 15.

Sullivan, D. M., D. F. Kehoe, and R. Smith. 1987. Measurement of trace levels of total aluminum in foods by atomic absorption spectrophotometry. Journal-Association of Official Analytical Chemists 70: 118-120.

Tabrizi, A. B. 2007. Cloud point extraction and spectrofluorimetric determination of aluminum and zinc in foodstuffs and water samples. Food Chemistry, 100: 16981703.
Tomljenovic, L. 2011. Aluminum and Alzheimer's disease: after a century of controversy, is there a plausible link? Journal of Alzheimer's Disease 23: 567-598.

Walton, J. R. 2006. Aluminum in hippocampal neurons from humans with Alzheimer's disease. Neurotoxicology 27: 385-394.

World Health Organization. 2014. Evaluation of Certain Food Additives and Contaminants: Seventy-seventh Report of the Joint FAO/WHO Expert Committee on Food Additives (Vol. 77). World Health Organization.

Wong, K. P. and R. C Alkire. 1990. Local chemistry and growth of single corrosion pits in aluminum. Journal of the Electrochemical Society 137: 3010-3015.

Yokel, R. A. 2006. Blood-brain barrier flux of aluminum, manganese, iron and other metals suspected to contribute to metal-induced neurode generation. Journal of Alzheimer's Disease 10: 223-253.

Zhao, J., H. J. Kim, J.Oh, W.Lee, S.Sakamoto and K. Kim. 2001. Cucurbit $[\mathrm{n}]$ uril derivatives soluble in water and organic solvents. Angewandte Chemie International 40: 4233-4235. 